\title{
Genetics of Symbiosis in Lotus japonicus: Recombinant Inbred Lines, Comparative Genetic Maps, and Map Position of 35 Symbiotic Loci
}

\author{
Niels Sandal, ${ }^{1}$ Thomas Rørby Petersen, ${ }^{1}$ Jeremy Murray, ${ }^{2}$ Yosuke Umehara, ${ }^{3}$ Bogumil Karas, ${ }^{2}$ \\ Koji Yano, ${ }^{4}$ Hirotaka Kumagai, ${ }^{3}$ Makoto Yoshikawa, ${ }^{4}$ Katsuharu Saito, ${ }^{5}$ Masaki Hayashi, ${ }^{6}$ Yasuhiro \\ Murakami, ${ }^{3}$ Xinwang Wang, ${ }^{3}$ Tsuneo Hakoyama, ${ }^{7}$ Haruko Imaizumi-Anraku, ${ }^{3}$ Shusei Sato, ${ }^{8}$ \\ Tomohiko Kato, ${ }^{8}$ Wenli Chen, ${ }^{3}$ Md. Shakhawat Hossain, ${ }^{3}$ Satoshi Shibata, ${ }^{3}$ Trevor L. Wang, ${ }^{9}$ \\ Keisuke Yokota, ${ }^{1}$ Knud Larsen, ${ }^{1}$ Norihito Kanamori, ${ }^{1}$ Esben Madsen, ${ }^{1}$ Simona Radutoiu, ${ }^{1}$ Lene H. \\ Madsen, ${ }^{1}$ Talida Gratiela Radu, ${ }^{1}$ Lene Krusell, ${ }^{1,10}$ Yasuhiro Ooki, ${ }^{11}$ Mari Banba, ${ }^{11}$ Marco Betti, ${ }^{12}$ \\ Nicolas Rispail, ${ }^{13}$ Leif Skøt, ${ }^{13}$ Elaine Tuck, ${ }^{13}$ Jillian Perry, ${ }^{14}$ Satoko Yoshida, ${ }^{14,15}$ Kate Vickers, ${ }^{14}$ \\ Jodie Pike, ${ }^{14}$ Lonneke Mulder, ${ }^{14}$ Myriam Charpentier, ${ }^{14}$ Judith Müller, ${ }^{14}$ Ryo Ohtomo, ${ }^{16}$ Tomoko Kojima, ${ }^{16}$ \\ Shotaro Ando, ${ }^{16}$ Antonio J. Marquez, ${ }^{12}$ Peter M. Gresshoff, ${ }^{17}$ Kyuya Harada, ${ }^{6}$ Judith Webb, ${ }^{13}$ \\ Shingo Hata, ${ }^{11}$ Norio Suganuma, ${ }^{7}$ Hiroshi Kouchi, ${ }^{3}$ Shinji Kawasaki, ${ }^{3}$ Satoshi Tabata, ${ }^{8}$ Makoto Hayashi, \\ Martin Parniske, ${ }^{14,15}$ Krzysztof Szczyglowski, ${ }^{2}$ Masayoshi Kawaguchi, ${ }^{5}$ and Jens Stougaard ${ }^{1}$ \\ ${ }^{1}$ Laboratory of Gene Expression, Department of Molecular Biology, University of Aarhus, Gustav Wieds Vej 10, DK-8000 \\ Aarhus C, Denmark; ${ }^{2}$ Agriculture and Agri-Food Canada, SCPFRC, 1391 Sandford Street, London, Ontario NV5 4T3, \\ Canada; ${ }^{3}$ National Institute of Agrobiological Sciences, 2-1-2 Kannon-dai, Tsukuba, Ibaraki, 305-8602, Japan; ${ }^{4}$ Department \\ of Biotechnology, Graduate School of Engineering, Osaka University, 2-1 Yamadaoka, Suita, Osaka 565-0871, Japan; \\ ${ }^{5}$ Department of Biological Sciences, Graduate School of Science, University of Tokyo, 7-3-1 Hongo, Bunkyo, Tokyo 113-0033; \\ ${ }^{6}$ Faculty of Horticulture, Chiba University, 648 Matsudo, Matsudo, Chiba 271-8510, Japan; ${ }^{7}$ Department of Life Science, \\ Aichi University of Education, Kariya, Aichi 448-8542, Japan; ${ }^{8}$ Kazusa DNA Research Institute, 1532-3 Yana, Kisarazu, \\ Chiba 292, Japan; ${ }^{9}$ John Innes Centre, Norwich Research Park, Colney, Norwich, NR4 7UH, England; ${ }^{10}$ Molecular Plant \\ Nutrition Group, Max Planck Institute of Molecular Plant Physiology, Am Mühlenberg 1, D-14476 Golm, Germany; \\ ${ }^{11}$ Laboratory of Plant Biochemistry, Graduate School of Biostudies, Kyoto University, Sakyo-ku, Kyoto 606-8502, Japan; \\ ${ }^{12}$ Facultad de Química, Universidad de Sevilla, Apartado 553, 41080 Sevilla, Spain; ${ }^{13}$ IGER, Department of Plant Genetics \\ and Breeding, Plas Gogerddan, Aberystwyth, Ceredigion SY23 3EB, Wales, U.K.; ${ }^{14}$ Sainsbury Laboratory, Norwich \\ Research Park, Colney, Norwich, NR4 7UH, England; ${ }^{15}$ Genetics Institute, Ludwig Maximilians Universität (LMU), \\ Maria-Ward-Str. 1a, D-80638, Germany; ${ }^{16}$ National Institute of Livestock and Grassland Science, 768 Senbonmatsu, \\ Nasushiobara, Tochigi 329-2793, Japan; ${ }^{17}$ ARC Centre of Excellence for Integrative Legume Research, \\ University of Queensland, Brisbane QId 4072, Australia
}

Submitted 14 June 2005. Accepted 12 September 2005.

Development of molecular tools for the analysis of the plant genetic contribution to rhizobial and mycorrhizal symbiosis has provided major advances in our understanding of plant-microbe interactions, and several key symbiotic genes have been identified and characterized. In order to increase the efficiency of genetic analysis in the model legume Lotus japonicus, we present here a selection of improved genetic tools. The two genetic linkage maps previously developed from an interspecific cross between $L$. japonicus Gifu and $L$. filicaulis, and an intraspecific cross between the two ecotypes $L$. japonicus Gifu and $L$. japonicus MG-20, were aligned through a set of anchor markers. Regions of linkage groups, where genetic resolution is obtained preferentially using one or the other parental com-

Corresponding author: Niels Sandal: E-mail: nns@mb.au.dk

Seeds of $L$. filicaulis $\times$ Gifu recombinant inbred lines may be obtained by E-mailing the corresponding author.

This article is in the public domain and not copyrightable. It may be freely reprinted with customary crediting of the source. The American Phytopathological Society, 2006. bination, are highlighted. Additional genetic resolution and stabilized mapping populations were obtained in recombinant inbred lines derived by a single seed descent from the two populations. For faster mapping of new loci, a selection of reliable markers spread over the chromosome arms provides a common framework for more efficient identification of new alleles and new symbiotic loci among uncharacterized mutant lines. Combining resources from the Lotus community, map positions of a large collection of symbiotic loci are provided together with alleles and closely linked molecular markers. Altogether, this establishes a common genetic resource for Lotus spp. A web-based version will enable this resource to be curated and updated regularly.

Additional keywords: symbiotic mutants.

Genetic analysis and application of genetic approaches in the model legume Lotus japonicus (Handberg and Stougaard 1992) has progressed rapidly. Several key genes important for symbiosis with mycorrhizal fungi, root nodule development, and other developmental processes have been identified using molecular 
genetic techniques. The developmental regulators Nin (Schauser et al. 1999) and Pfo (Zhang et al. 2003) were isolated by transposon tagging, whereas map-based cloning led to the molecular characterization of Harl, SymRK, Nfrl, Nfr5, Castor, and Pollux involved in autoregulation, Nod-factor signal perception or signal transduction (Imaizumi-Anraku et al. 2005; Krusell et al. 2002; Madsen et al. 2003; Nishimura et al. 2002a; Radutoiu et al. 2003; Schauser et al. 1999; Stracke et al. 2002). Genetic loci required for the early stages of endosymbiosis have attracted particular interest. Diallelic crosses together with phenotypical studies defined seven loci (SymRK, Nup133, Castor, Pollux, Sym6, Sym15, and Sym24) in the common pathway required for both rhizobial and mycorrhizal symbioses (Kistner et al. 2005). Map-based cloning of these loci either has been accomplished or is well advanced. A similar interest is now advancing the genetic dissection of nodule organogenesis and function by using the Fix $^{-}$mutants arrested at later stages of nodule development or impaired in nodule function. Cloning of the L. japonicus Sst1 sulfate transporter, which is required in nitrogen-fixing root nodules, represents the first successful example of such an approach (Krusell et al. 2005).

Continuous isolation of new plant mutant lines is important for comprehensive genetic dissection of symbiosis. Thus far, seven independent mutant populations have been generated by chemical (ethyl methane sulphonate) mutagenesis (Kawaguchi et al. 2002; Márquez et al. 2005; Perry et al. 2003; Szczyglowski et al. 1998; Webb et al. 2005; P. M. Gresshoff, unpublished data), four populations were obtained after T-DNA or transposon insertion mutagenesis (Buzas et al. 2005; Schauser et al. 1998; Thykjær et al. 1995; Webb et al. 2000), and two populations were made by either fast neutrons (P. M. Gresshoff, unpublished data) or tissue culture (Y. Umehara and H. Kouchi, unpublished data). More than 400 symbiotic Lotus mutant lines were identified and more are likely to follow. Assignment of these mutant lines to complementation groups is the next logical step in order to determine the overall number of loci involved, to identify all alleles that contribute to phenotypic variation of the mutants, and for genotyping of loci. However, diallelic crossing is a relatively slow process where progress is determined by the length of a generation time and slowed by a continuously increasing number of individual crosses necessary to keep up with mutant isolation programs. Given the number of symbiotic mutant lines already available and considering the time used to define seven complementation groups with a total of 26 alleles constituting the common symbiotic pathway (Kistner et al. 2005), this approach is unlikely to encompass all alleles in the near future. Detection of alleles in already cloned genes using the TILLING facility (Perry et al. 2003) is one way forward to significantly decrease the number of diallelic crosses needed, and this technique will become increasingly effective as mutational saturation is approached. Further improvement of genetic maps and mapping approaches also can diminish the effort needed. So far, two genetic maps have been established, one based on an interspecific cross between L. filicaulis and L. japonicus ecotype Gifu (Sandal et al. 2002) and one from an L. japonicus ecotype cross between Gifu and Miyakojima MG-20 (Asamizu et al. 2003; Hayashi et al. 2001; Kaneko et al. 2003; Nakamura et al. 2002; Sato et al. 2001). Both maps have advantages, and alignment of the two maps enables direct transfer of information between them. This will be especially useful in regions where suppression of recombination or segregation distortion limits genetic resolution in one of the crosses.

In this article, we present improved genetic tools, such as recombinant inbred lines (RILs), alignment of genetic maps through anchor markers, a selection of reliable markers for faster mapping of new loci, and map positions of a collection of symbiotic loci, providing a common framework for more effi- cient identification of new alleles and new symbiotic loci among uncharacterized mutant lines.

\section{RESULTS}

\section{Map alignment.}

Three ecotypes of L. japonicus (Gifu, MG-20, and Funakura) and two related species (L. filicaulis and L. burttii) have been used or suggested as parents for various aspects of genetics (Handberg and Stougaard 1992; Jiang and Gresshoff 1997; Kawaguchi 2000; Kawaguchi et al. 2005; Sandal et al. 2002). All have advantages and disadvantages to be considered before choosing crossing partners to establish an appropriate segregating population for a particular genetic analysis. Positional cloning relies on genetic linkage analysis and, at present, two maps provide marker information. In order to optimize positional cloning efforts, it is crucial to choose a crossing partner and a linkage map with genetic resolution in the chromosomal region of interest. Regions of distorted segregation and suppression of recombination were found in both of the genetic linkage maps available in Lotus spp. (Hayashi et al. 2001; Sandal et al. 2002). In the interspecific L. filicaulis $\times$ L. japonicus Gifu map, distorted segregation was observed in the middle part of linkage group I and suppression of recombination on the upper part of linkage groups II and III and in the lower middle part of linkage group I (Pedrosa et al. 2002; Sandal et al. 2002). In the Gifu $\times$ MG-20 ecotype map, suppression of recombination was found in a region of Gifu linkage group I at 10.8 centimorgans $(\mathrm{cM})$ corresponding to the MG-20 linkage group I 0-cM region. This region is close to the translocation break point between chromosome 1 of Gifu and chromosome 2 of MG-20 (Hayashi et al. 2001). To provide detailed information on genetic resolution, alignment of genetic maps through anchor markers is required. A source of such anchor markers was established by the Lotus genome-sequencing program. More than 1,000 microsatellite markers were developed to anchor sequenced TAC clones onto the MG-20 × Gifu genetic map (Asamizu et al. 2003; Hayashi et al. 2001; Kaneko et al. 2003; Nakamura et al. 2002; Sato et al. 2001). We took advantage of these markers and tested them in the L. filicaulis $\times$ Gifu F2 mapping population. Among microsatellite markers tested, $39 \%$ were codominant markers, $44 \%$ were dominant markers, and $17 \%$ showed no size differences in the gel system used to separate polymerase chain reaction (PCR) fragments. The set of 160 anchor markers identified made it possible to align the two genetic F2 maps. This alignment reveals colinearity along all Lotus linkage groups. More noticeable are differences in genetic distances between the L. filicaulis $\times$ Gifu and MG-20 × Gifu F2 maps, especially in linkage group I (Fig. 1). Inversions on the long arm of chromosome 1 and the short arm of chromosome 3 between L. filicaulis and Gifu and the translocation between chromosome 1 of Gifu and chromosome 2 of MG-20 (Hayashi et al. 2001; Pedrosa et al. 2002) might explain some of these differences. The aligned genetic maps are shown in Figure 1 and the regions where one of the linkage maps provides better genetic resolution are indicated.

The total length of the genetic map for L. japonicus Gifu $\times$ L. japonicus MG-20 is $439 \mathrm{cM}$ and for L. filicaulis $\times$ L. japonicus Gifu it is $490 \mathrm{cM}$. The major difference between the previous version of the L. filicaulis $\times L$. japonicus Gifu map (Sandal et al. 2002) and the new version is the addition of 62 $\mathrm{cM}$ on the top of linkage group IV from TM0525 to TM0075.

\section{Recombinant inbred lines.}

Stabilized mapping populations, so-called RILs, are important resources for future mapping of single genes as well as quantitative trait loci (QTLs). The advantage of RILs is the genetically stabilized recombination events fixed in their ge- 
nomes. Almost all loci are homozygous and, furthermore, the number of recombination events represented is expected to be doubled compared with the F2, giving a better resolution of the map (Burr and Burr 1991). Progeny of RILs will have an identical genotype and can be shared between laboratories, making direct comparison of mapping data and phenotypic characterization from different laboratories possible. Furthermore, the increase in the number of homozygous loci will be expected to increase the phenotypic differences between lines and make mapping of dominant markers more precise. The RILs have been developed from the two original F2 mapping populations (discussed above) to the S8 generation (theoretically, 99.22\% homozygotic loci). Until now, 79 RILs have been developed for the L. filicaulis $\times$ Gifu population. The final number of RILs is expected to be approximately 100 . In addition, 149 RILs are available from Gifu $\times$ MG-20 and the final number of these RILs is expected to be 205. Primary mapping data for these two RIL populations are available online.

Alignment of the L. filicaulis $\times$ Gifu RIL-based genetic linkage map and the two F2 maps was performed by mapping 108 microsatellite markers on the 79 L. filicaulis $\times$ Gifu RILs. To as- certain the quality of mapping data and maps, both Mapmaker and Joinmap programs were used together with manual color maps. Generally, the order of markers from the F2 maps was confirmed by the L. filicaulis $\times$ Gifu RIL map. Some chromosomal regions were better resolved in the RIL. One example is in a part of linkage group VI (chromosome 6) that was not resolved in the MG-20-based F2 map, in which 11 markers mapped to the same position at $48.6 \mathrm{cM}$. Using RILs, it was possible to resolve some of these markers in the order listed from the top down: (TM0066, TM0437, TM0944), TM0367, TM0630, TM1525, (TM1116, TM0139), TM1035 (Fig. 1, TM0367 and TM0139). The markers that still cannot be resolved are shown in brackets.

Direct comparison of allele distributions of 48 loci of the MG-20 $\times$ Gifu and 60 loci in L. filicaulis $\times$ Gifu RIL populations allowed assessment of allele representations along the six linkage groups. In RILs, 50\% representation of each of the homozygous alleles is expected for individual loci. Gifu $\times$ MG20 RILs showed only minor distortions, whereas L. filicaulis $\times$ Gifu RILs had some segregation distortion on parts of linkage groups I, II, and VI (Fig. 2). In the F2, L. filicaulis $\times$ Gifu

\section{FxG I}

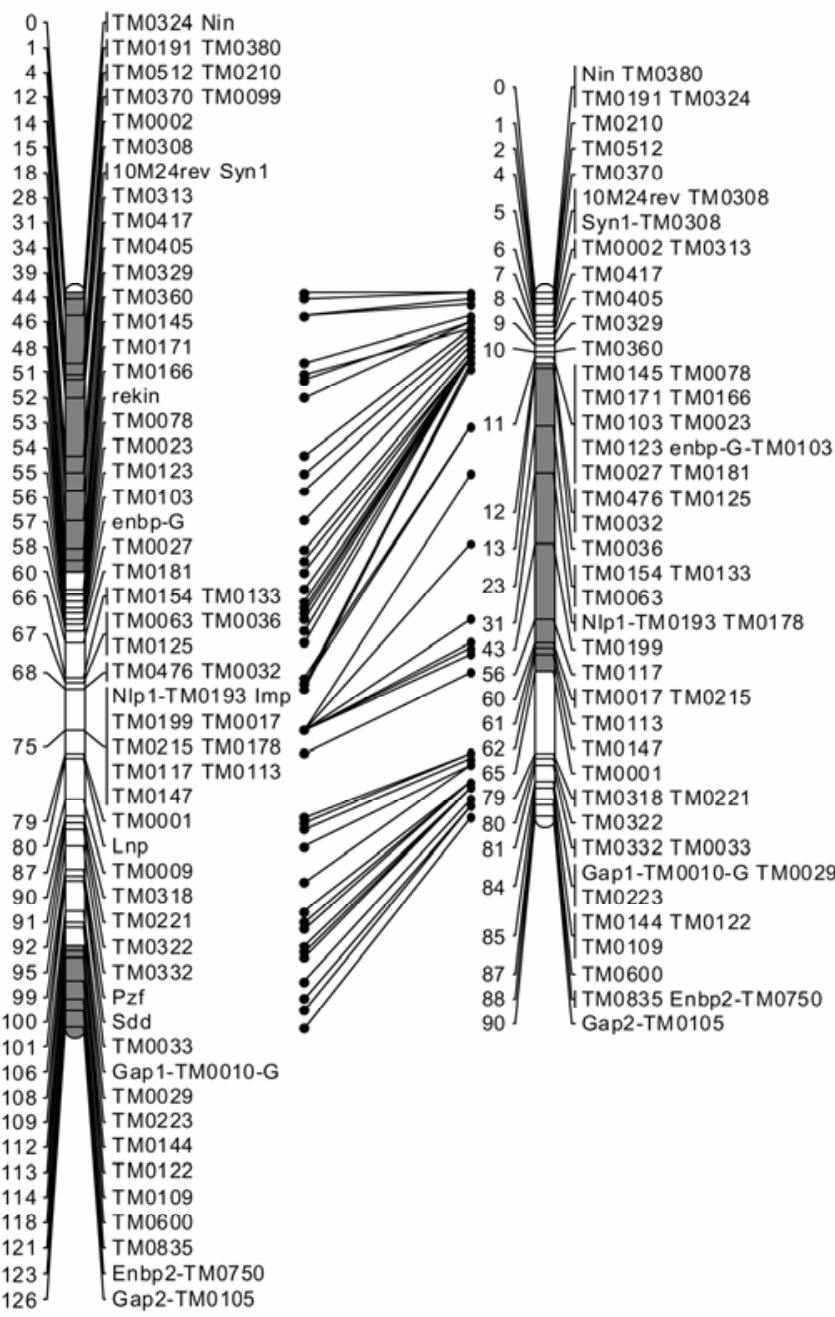

\section{FxG II GxM II}

Fig. 1. Alignment of Lotus filicaulis $\times$ L. japonicus Gifu $(\mathrm{F} \times \mathrm{G})$ and $L$. japonicus $\mathrm{Gifu} \times$ L. japonicus $\mathrm{MG}-20(\mathrm{G} \times \mathrm{M})$ map distances on the six linkage groups. The map distances were determined by Mapmaker based on the F2 populations. The map positions are from L. japonicus Gifu where the region from Nin (0 centimorgans $[\mathrm{cM}])$ to TM0360 $(10 \mathrm{cM})$ is located on the top of linkage group I. TM numbers refer to codominant microsatellite markers. Regions where one of the linkage maps provides better genetic resolution are indicated in gray. 
showed a strong preference for the Gifu allele on linkage group III (Sandal et al. 2002). Unexpectedly, this has stabilized to a certain degree in the RILs, giving rise to an identical number of Gifu and L. filicaulis alleles from 1 to $40 \mathrm{cM}$ and a preference for either L. filicaulis or Gifu alleles from 40 to $70 \mathrm{cM}$ and 70 to $85 \mathrm{cM}$ regions, respectively.

In theory, the number of heterozygous loci in the RILs should be very low $(0.78 \%)$. Surprisingly, RILs based on the L. filicaulis cross still have several heterozygous loci present in S8, especially for the upper part of linkage group III. In this region, 24 lines are homozygous L. filicaulis, 27 lines are homozygous Gifu, and 29 lines are heterozygous. Although the frequency of heterozygous plants is lower than in the F2, there apparently is a selection for heterozygous plants throughout the generations. The only other region showing more heterozygous plants than expected is the upper part of linkage group II in the L. filicaulis cross (Fig. 2). These two regions, linkage group II from TM0134 (2.4 cM) to TM0053 (9.2 cM) and linkage group III from the top to TM0005 at $35.6 \mathrm{cM}$ in the Gifu $\times$ MG-20 map, correspond to two regions with suppression of recombination in the $\mathrm{F} 2$ for the L. filicaulis-based map.
Recombination in this region of chromosome 2 remains rare in RILs, whereas the region from chromosome 3 remains without recombinations in RILs. Excess heterozygozity could be caused by an advantage in viability for heterozygotes in a particular locus. An overlapping suppression of recombination caused by the large inversion found on chromosome 3 (Pedrosa et al. 2002) would expand such a selection to encompass a larger chromosomal segment. This phenomenon was found in Drosophila spp., where some populations had a high proportion of heterozygotes in inverted regions (Dobzhansky and Pavlovsky 1958). The excess of heterozygotes probably is related to heterosis and functional overdominance or to pseudo-overdominance, where the viability advantage of opposite parental genotypes at two linked loci leads to a selection for heterozygotes (Mitchell-Olds 1995).

\section{Map positions of Sym genes.}

L. japonicus has been chosen as a model plant for symbiotic interactions with rhizobia and mycorrhizal fungi. This has led to the isolation and characterization of important symbiotic genes such as Nin, Harl, Astray, SymRK, Castor, Pollux, Nfrl,
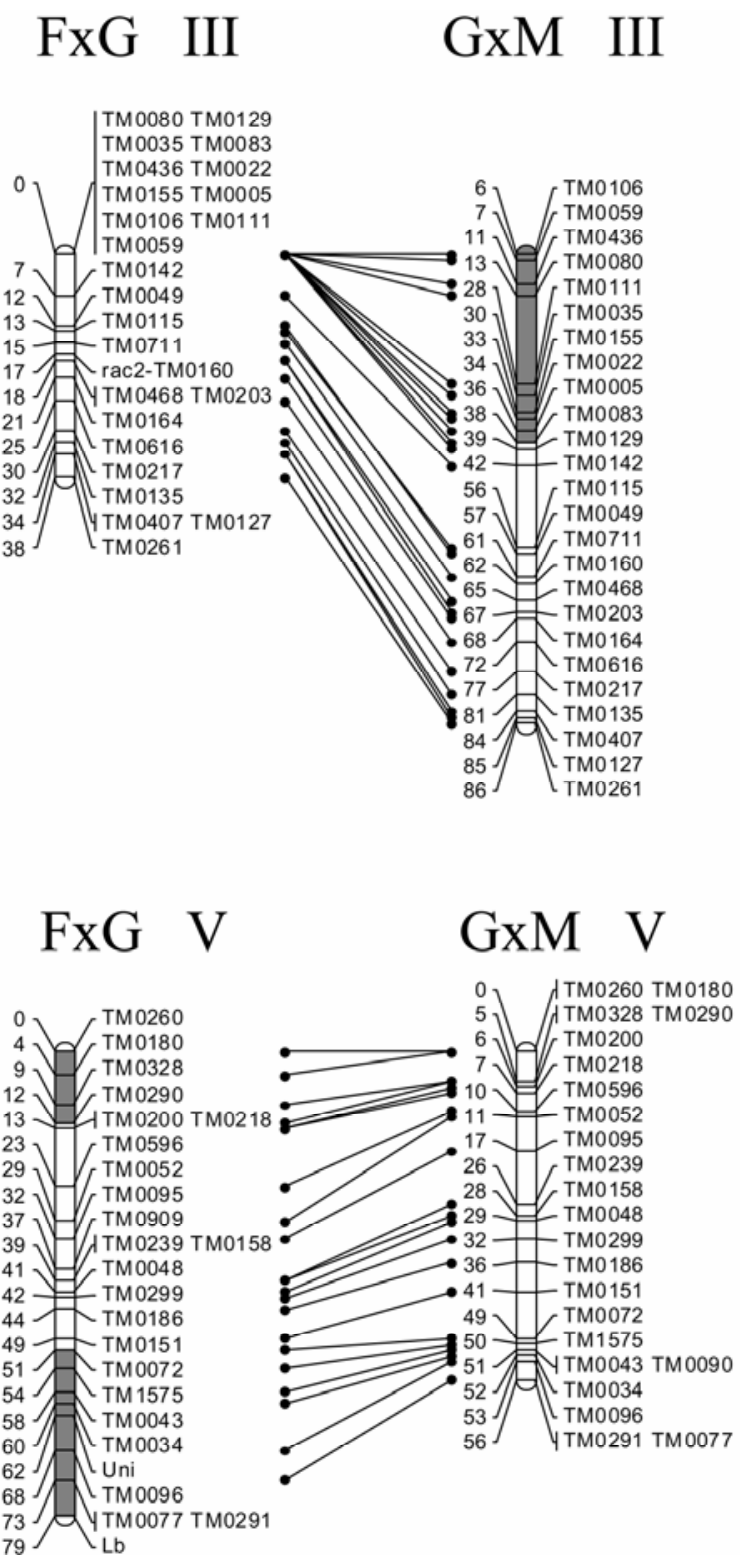
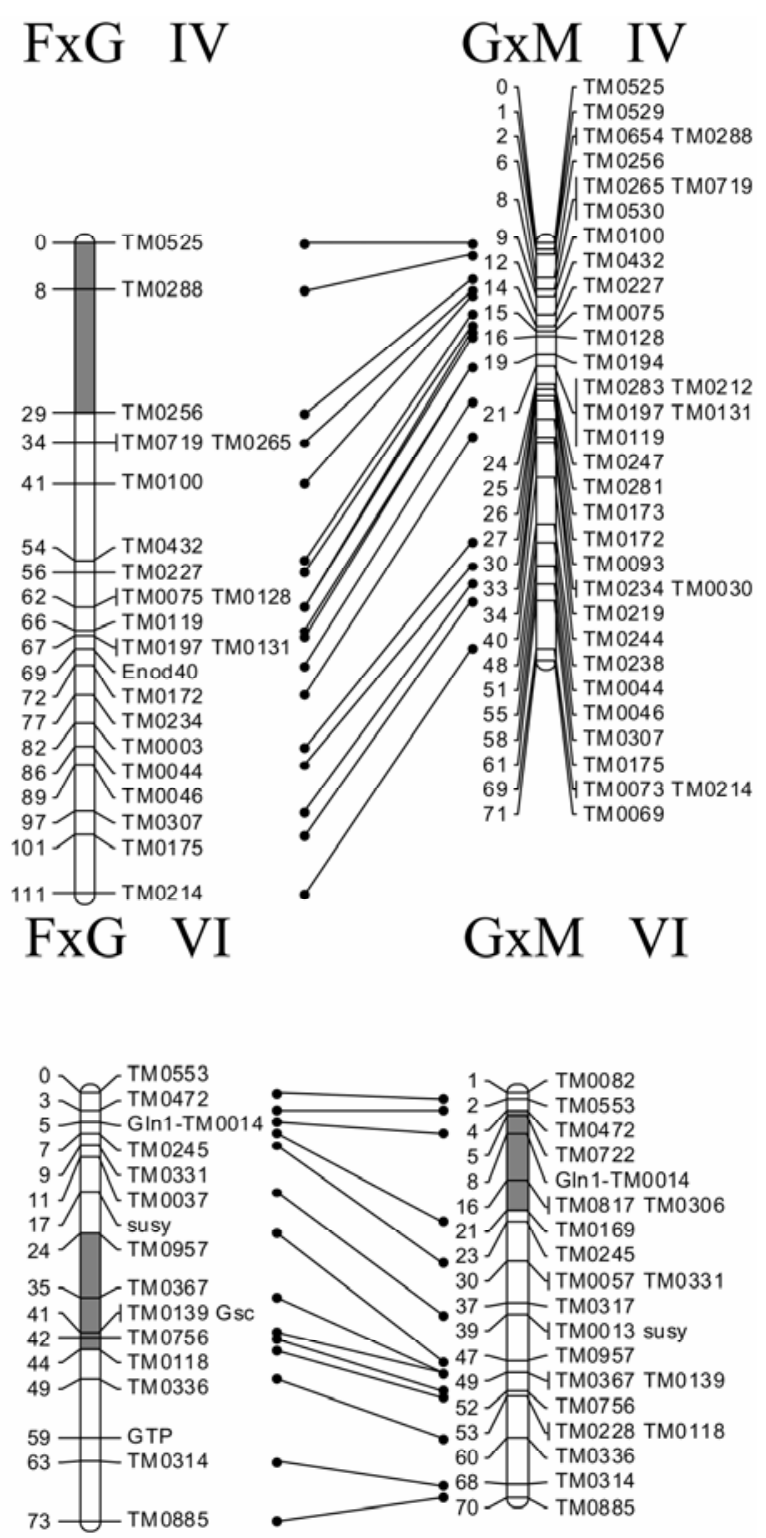

Fig. 1. Continued from preceding page. 

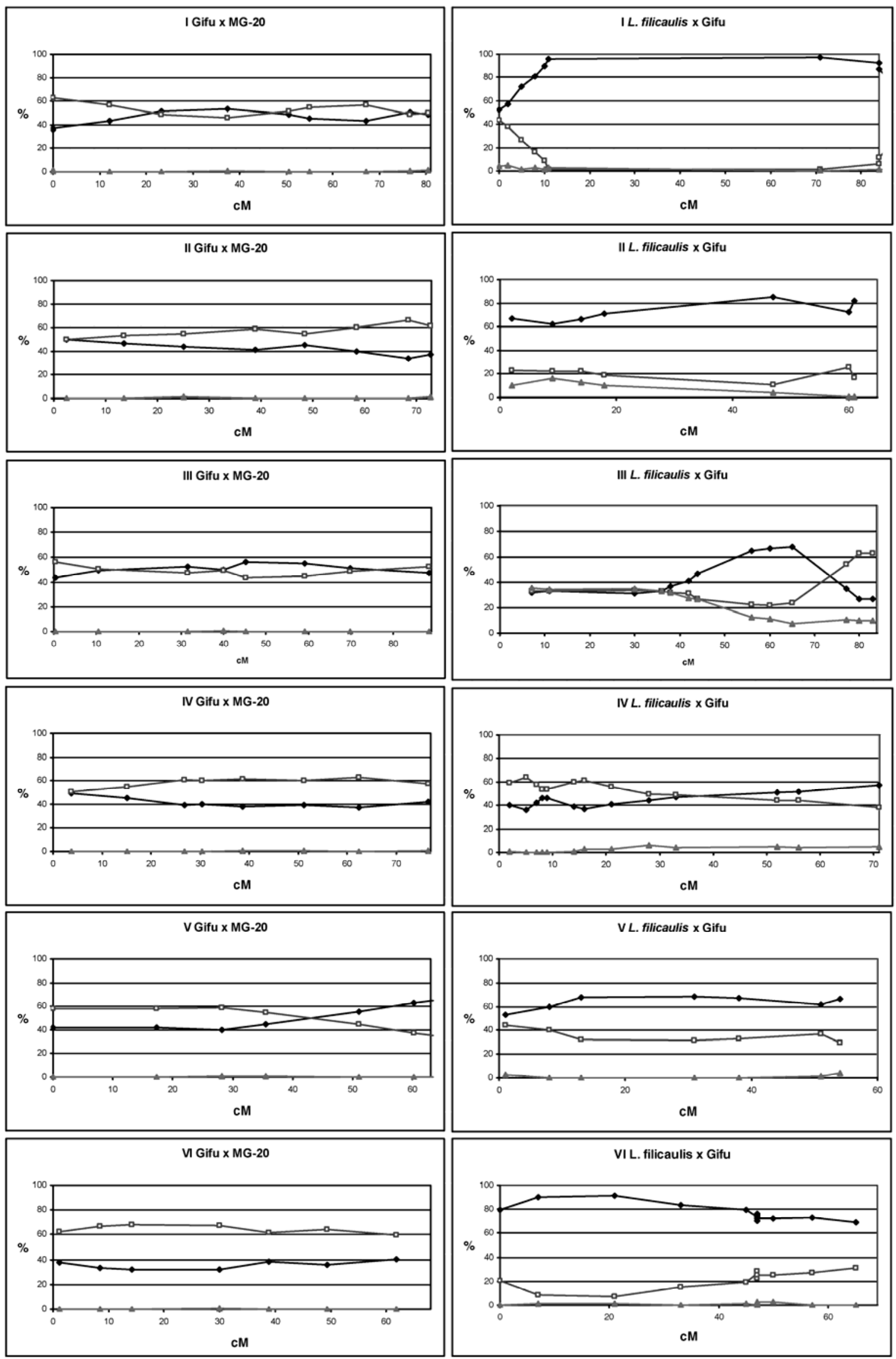

Fig. 2. Segregation of codominant markers in recombinant inbred lines based on Lotus japonicus Gifu $(\checkmark) \times$ L. japonicus MG-20 ( $\square$ ), on the left, and $L$. filicaulis $(\square) \times$ L. japonicus Gifu $(\diamond)$, on the right. Allele distributions are shown along linkage groups I to VI. Heterozygous (h) plants are indicated with $\triangle$. 
Nfr5, and Sst1 (Imaizumi-Anraku et al. 2005; Krusell et al. 2002, 2005; Madsen et al. 2003; Nishimura et al. 2002a and b; Radutoiu et al. 2003; Schauser et al. 1999; Stracke et al. 2002) and additional genes are being cloned. Several groups are pursuing positional cloning and characterization of different genes that are important for endosymbiosis. To avoid unproductive duplication of work, it is important to establish a common reference of Sym loci and to compare map positions for new mutations isolated by different groups. A number of Sym gene map positions already have been published for Lotus spp. (ImaizumiAnraku et al. 2005; Kawaguchi et al. 2005; Nishimura et al. 2002a; Sandal et al. 2002; Stracke et al. 2002; Suganuma et al. 2003; Tansengco et al. 2004). We have expanded the number of mapped loci by mapping 16 new loci and indicating the tentative alleles mapping in the corresponding genetic region as defined by flanking microsatellite markers (Tables 1 and 2). The combined map of 35 Sym genes is shown in Figure 3. This combined effort shows that at least $35 \mathrm{Sym}$ loci, including 11 that are characterized by a $\mathrm{Nod}^{-}$phenotype, 9 with a Hist ${ }^{-}$phenotype, $8 \mathrm{Fix}^{-}$ lines, and 3 hypernodulating mutants, have been found in $L$. japonicus. Based on the proposed genetic nomenclature (Stougaard et al. 1999), Table 2 summarizes information on loci and alleles.
Fast mapping of new loci.

Using one or two microsatellite markers from each linkage group for cosegregation analysis, it is possible to determine the chromosomal position of a locus very quickly. We have compiled a list of recommended microsatellite markers for linkage group assignment (Table 3). In addition, a red (Gifu)/green (recessive MG-20) stem color (Vic6) locus mapping between TM0377 (29.0 cM) and TM1403 (34.7 cM) provides a visible marker on linkage group II. A low-resolution mapping procedure using, for example, 16 to 30 mutant plants can rapidly indicate an approximate map position. Note that the top of Gifu chromosome 1 and the bottom of MG-20 chromosome 2 will appear linked during a segregation analysis due to crossover between translocated regions. Map-based selection of candidates for complementation analysis has become easier and faster than performing more classical complementation tests to all sym mutants with a similar phenotype (Sandal et al. 2005). This approach has been tested with three new symbiotic mutant lines, 282-641, 282-643, and LKL486, that showed a Nod $^{-}$phenotype. This low-resolution mapping resulted in map positions close to SymRK, Nupl33/Nin, and Castor, respectively (Table 2). These new, likely alleles, as indicated from

Table 1. Phenotype and flanking microsatellite markers for Lotus japonicus Sym genes ${ }^{\mathrm{a}}$

\begin{tabular}{|c|c|c|c|c|c|c|c|c|c|}
\hline sym locus & Phenotype & Chr. & $\begin{array}{l}\text { Marker at } \\
\text { the gene }\end{array}$ & cM & $\begin{array}{l}\text { Upper flanking } \\
\text { marker }\end{array}$ & cM & $\begin{array}{c}\text { Lower flanking } \\
\text { marker }\end{array}$ & cM & Reference \\
\hline $\operatorname{nin} \#$ & Nod-, Ami+ & 1,2 & TM0102 & 0 & & & TM0324 & 0.4 & Schauser et al. 1999 \\
\hline nup133 \# & Nod-, Ami- & 1,2 & $\ldots$ & 0.8 & TM0324 & 0.4 & TM0370 & 3.6 & Kanamori et al.* \\
\hline$n f r l \#$ & Nod-, Ami+ & 1,2 & TM0545, & 48 & ТМ0370 & 36 & TM0000 & 56 & Radutciu et al 2003 \\
\hline lot 1 & Nod+-, Ami+ & 1 & ... & $\ldots$ & TM0166 & 10.8 & TM0027 & 10.8 & Ooki et al. 2005 \\
\hline sym 24 & Nod-, Ami- & 1 & & $\ldots$ & TM0016 & 10.8 & TM0027 & 10.8 & $\begin{array}{l}\text { Szczyglowski et al. 1998; } \\
\text { Kawaguchi et al. } 2005\end{array}$ \\
\hline alb1 & Hist-, Ami+ & 1 & $\ldots$ & $\ldots$ & TM0016 & 10.8 & TM0027 & 10.8 & Kawaguchi et al. 2005 \\
\hline sym70 & Nod-, Ami+ & 1 & $\ldots$ & $\ldots$ & TM0016 & 10.8 & TM0125 & 12.4 & Murakami et al.* \\
\hline sym102 & Fix- & 1 & $\ldots$ & $\ldots$ & TM0671 & 19.6 & TM0498 & 22.9 & Umehara and Kouchi* \\
\hline klavier & Nod++ & 1 & $\ldots$ & $\ldots$ & TM1325 & 43.0 & TM0215 & 49.0 & Oka-Kira et al. in press \\
\hline fen1 & Fix-, Ami+ & 1 & $\ldots$ & $\ldots$ & TM0001 & 65.3 & TM0064 & 67.3 & Suganuma* \\
\hline sym 80 & Hist-, Ami+ & 1 & $\ldots$ & $\ldots$ & TM0122 & 83.8 & TM0105 & 89.0 & Yano, Kawaguchi, and Hayashi* \\
\hline $\operatorname{sym} 40$ & Hist- & 1 & $\ldots$ & $\ldots$ & TM0109 & 84.6 & TM0105 & 89.0 & Yokota, Sandal, and Stougaard* \\
\hline castor \# & Nod-, Ami- & 1 & TM1494 & 89.4 & TM0105 & 89.0 & & & $\begin{array}{l}\text { Senoo et al. 2000; } \\
\text { Imaizumi-Anraku et al. } 2005\end{array}$ \\
\hline sst1 \# & Fix-, Ami+ & 2 & TM0610 & 13.2 & TM0153 & 12.4 & TM0660 & 14.4 & Krusell et al. 2005 \\
\hline symRK \# & Nod-, Ami- & 2 & TM0541 & 51.0 & TM0076 & 45.3 & TM0230 & 51.4 & Stracke et al. 2002 \\
\hline sym6 & Hist-, Ami- & 2 & & & TM0076 & 45.3 & TM0021 & 64.2 & $\begin{array}{l}\text { Schauser et al. 1998; } \\
\text { Yano, Kawaguchi, and Hayashi; } \\
\text { Vickers, Pike, and Parniske* }\end{array}$ \\
\hline$n f r 5 \#$ & Nod-, Ami+ & 2 & TM0522 & 61.4 & TM0257 & 58.6 & TM0250 & 62.6 & Madsen et al. 2003 \\
\hline $\operatorname{sym} 8$ & Hist-, Ami+ & 3 & $\ldots$ & $\ldots$ & & & & & Schauser et al. 1998 \\
\hline sym104 & Fix-, Ami+ & 3 & $\ldots$ & $\ldots$ & TM0996 & 21.9 & TM0111 & 27.6 & Hossain, Umehara, and Kouchi* \\
\hline sym15 & Nod-, Ami- & 3 & & & TM0022 & 33.6 & TM0005 & 35.6 & $\begin{array}{l}\text { Senoo et al. 2000; } \\
\text { Yoshida and Parniske; } \\
\text { Imaizumi-Anraku and Kawasaki* }\end{array}$ \\
\hline harl \# & Nod++, Ami++ & 3 & TM0258 & 78.0 & TM0217 & 76.4 & TM0135 & 80.8 & $\begin{array}{l}\text { Krusell et al. 2002; Nishimura et al. } \\
\text { 2002a; Solaiman et al. } 2000\end{array}$ \\
\hline $\operatorname{srh} 1$ & $\ldots$ & 3 & $\ldots$ & $\ldots$ & TM1419 & 84.0 & TM0127 & 84.8 & Karas et al. 2005 \\
\hline vrhl & $\ldots$ & 3 & $\ldots$ & $\ldots$ & TM1419 & 84.0 & TM0127 & 84.8 & Karas et al. 2005 \\
\hline senl & Fix-, Ami+ & 4 & $\ldots$ & $\ldots$ & TM0530 & 8.4 & TM0182 & 8.8 & Suganuma et al. 2003 \\
\hline sym10 & Hist-, Ami+ & 4 & $\ldots$ & $\ldots$ & TM0182 & 8.8 & TM0283 & 20.5 & Petersen, Sandal, and Stougaard* \\
\hline sym 67 & Hist- & 4 & $\ldots$ & $\ldots$ & TM0227 & 14.4 & TM0347 & 15.6 & Yokota, Sandal, and Stougaard* \\
\hline sym105 & Fix-, Ami+ & 4 & $\ldots$ & $\ldots$ & TM0126 & 24.6 & TM0173 & 25.8 & Hossain, Umehara, and Kouchi* \\
\hline ign1 & Fix-, Ami+ & 5 & $\ldots$ & $\ldots$ & TM0260 & 0 & TM0180 & 0.4 & Kumagai et al.* \\
\hline sym 7 & Hist-, Ami+ & 5 & $\ldots$ & $\ldots$ & TM0095 & 16.9 & TM0913 & 22.3 & Schauser et al. 1998; Shibata et al.* \\
\hline crinkle & Hist-, Ami- & 5 & $\ldots$ & $\ldots$ & TM0151 & 43.1 & TM0024 & 43.4 & Tansengco et al. 2004 \\
\hline prh1 & & 5 & $\ldots$ & $\ldots$ & TM0494 & 41.8 & TM0696 & 47.0 & Karas et al. 2005 \\
\hline sym 43 & Fix-, Ami+ & 5 & $\ldots$ & $\ldots$ & TM0072 & 49.0 & TM0043 & 51.0 & $\begin{array}{l}\text { Petersen, Sandal, and Stougaard; } \\
\text { Umehara and Kouchi* }\end{array}$ \\
\hline astray \# & Nod++, Ami+ & 6 & TM0085 & 29.6 & TM0821 & 27.8 & TM1374 & 29.8 & Nishimura et al. 2002b \\
\hline rhll & & 6 & & $\ldots$ & TM0037 & 34.9 & TM0140 & 38.1 & Karas et al. 2005 \\
\hline pollux \# & Nod-, Ami- & 6 & TM0885 & 70.2 & TM0314 & 68.1 & $\ldots$ & $\ldots$ & Imaizumi-Anraku et al. 2005 \\
\hline
\end{tabular}

a Map positions shown are for L. japonicus Gifu from the cross to MG-20. Chromosome (Chr.) 1,2 means that the gene is located in the region that is translocated between Gifu chromosome 1 and MG-20 chromosome 2; $\mathrm{cM}=$ centimorgans; $*$ = this publication; and \# = cloned genes. 
low-resolution mapping, are shown in Table 2. The table also lists confirmed alleles together with a summary of relevant information. New alleles identified through sequencing of previously isolated Sym genes are shown in Table 4 together with the nature of the identified mutation.

\section{DISCUSSION}

In this article, we present the map positions of 35 Sym genes from L. japonicus (Fig. 3) and compile a list of possible alleles awaiting confirmation by complementation or sequencing (Table

Table 2. Summary list of Lotus mutants and alleles ${ }^{\mathrm{a}}$

\begin{tabular}{|c|c|c|c|c|c|c|}
\hline Sym locus & Phenotype & Alleles & $\begin{array}{l}\text { Likely mutant } \\
\text { alleles }\end{array}$ & $\begin{array}{l}\text { Original line names of } \\
\text { confirmed mutant lines }\end{array}$ & $\begin{array}{l}\text { Previous } \\
\text { name }\end{array}$ & Reference \\
\hline Nin & Nod-, Ami+ & nin-1 and nin-7 & $\cdots$ & $96.1 \mathrm{M} 2, \mathrm{KL} 577$ & sym 20 & Schauser et al. 1999 \\
\hline$N f r l$ & Nod-, Ami+ & $n f r l-1$ to 4 & $\ldots$ & $\begin{array}{l}282-118,282-665, \text { N38, } \\
\text { G71-23 }\end{array}$ & $\begin{array}{l}\text { syml, } \\
\text { sym106 }\end{array}$ & $\begin{array}{l}\text { Radutoiu et al. 2003; Chen, Umehara, } \\
\text { and Kouchi; Kawaguchi* }\end{array}$ \\
\hline Nfr5 & Nod-, Ami+ & $n f r 5-1$ to -5 & $\ldots$ & $\begin{array}{l}\text { 282-894, KL865, EMS223, } \\
\text { S4-1, S58-1, B31-1 }\end{array}$ & sym5 & $\begin{array}{l}\text { Madsen et al. 2003; Murray, Karas, and } \\
\text { Szczyglowski* }\end{array}$ \\
\hline Sym70 & Nod-, Ami+ & sym70-1 and 2 & $\ldots$ & cAc18.4 & sym35 & Kawaguchi et al. 2002; Murakami et al.* \\
\hline SymRK & Nod-, Ami- & symRK -1 to -11 & sym $84,282-641$ & $\begin{array}{l}\text { 282-287, 282-288, cAc41, } \\
\text { KL481, cAc67.6, EMS34, } \\
\text { EMS61, SL160-2,3,4,5,6, } \\
\text { SL605-2,3, SL1951- } \\
2,3,4,5,6,7, \text { SL3472-2, 8-4H }\end{array}$ & sym2 & $\begin{array}{l}\text { Stracke et al. 2002; Yoshida and } \\
\text { Parniske } 2005\end{array}$ \\
\hline Castor & Nod-, Ami- & castor -1 to -20 & $\begin{array}{l}\text { S41-1, S46-1, } \\
\text { LKL486, B68- } \\
\text { B, B22-A, B32- } \\
\text { BA }\end{array}$ & $\begin{array}{l}\text { 282-227, EMS1749, EMS46, } \\
\text { 25-5A, 24-8B, N5, N10, } \\
\text { G00472, G00716, G00862, } \\
\text { M89-27, SL3251-2, SL820- } \\
\text { 3, SL1715-2, SL1966-3, } \\
\text { SL3160-3, SL6812-2, } \\
\text { KL549, G00532-21, } \\
\text { LKL186-4 }\end{array}$ & $\begin{array}{l}\text { sym } 4, \\
\text { sym } 22, \\
\text { sym } 71, \\
\text { sym } 64\end{array}$ & $\begin{array}{l}\text { Senoo et al. 2000; Imaizumi-Anraku et } \\
\text { al. } 2005\end{array}$ \\
\hline Pollux & Nod-, Ami- & pollux -1 to -10 & $\begin{array}{l}\text { S49-DA, } \\
\text { LKL302, S30, } \\
\text { B50-E, SL729- } \\
5\end{array}$ & $\begin{array}{l}\text { EMS70, EMS167, 29-2A, } \\
\text { SL571-2, SL3130-2, } \\
\text { SL5691-3, SL1899-2, } \\
\text { SL159-3, SL405-6, SL1070-2 }\end{array}$ & sym 23 & Imaizumi-Anraku et al. 2005 \\
\hline Nup133 & Nod-, Ami- & nup 133-1 to -4 & $\begin{array}{l}\text { un3, Sup12, } \\
\text { B9-A, B80-A, } \\
\text { B88-B2, B83- } \\
\text { B, B62-D }\end{array}$ & $\begin{array}{l}5371-22,2557-1, \operatorname{cac} 33.1 \\
\text { EMS } 247\end{array}$ & $\begin{array}{l}\text { sym3, } \\
\text { sym26 }\end{array}$ & Schauser et al. 1998; Kanamori et al.* \\
\hline Sym15 & Nod-, Ami- & $\begin{array}{l}\text { sym } 15-1 \text { to } 2 \text { and } \\
\text { sym } 72\end{array}$ & S95-B & cAc57, 282-1078, 8-1G, N20 & $\ldots$ & $\begin{array}{l}\text { Schauser et al. 1998; Senoo et al. 2000; } \\
\text { Kawaguchi et al. 2002; Imaizumi- } \\
\text { Anraku and Kawasaki* }\end{array}$ \\
\hline Sym 24 & Nod-, Ami- & $\begin{array}{l}\text { sym } 24, \text { sym } 73 \text {, } \\
\text { and sym } 85\end{array}$ & $\cdots$ & EMS76, 1-1E, 1-6F & $\begin{array}{l}\text { sym } 73 \text {, } \\
\text { sym } 85\end{array}$ & $\begin{array}{l}\text { Szczyglowski et al. 1998; Kawaguchi et } \\
\text { al. 2002; Kawaguchi et al. 2005; Pike } \\
\text { and Parniske* }\end{array}$ \\
\hline Sym6 & Hist-, Ami- & $\begin{array}{l}\text { sym6-1, sym6-2, } \\
\text { sym30, sym } 82\end{array}$ & pASacI124 & $\begin{array}{l}\text { 10512.9, 1962-124, } \\
\text { EMS126, N4 }\end{array}$ & $\begin{array}{l}\text { sym } 30 \\
\text { sym } 82\end{array}$ & $\begin{array}{l}\text { Schauser et al. 1998; Szczyglowski et } \\
\text { al. 1998; Yano, Kawaguchi, and } \\
\text { Hayashi; Vickers, Pike, and Parniske* }\end{array}$ \\
\hline Sym7 & Hist-, Ami+ & sym7 and sym101 & sym7-1 to 11 & $\begin{array}{l}\text { 312-133, G85-21, G90-23, } \\
\text { G101-22, G106-21, cAc61, } \\
\text { KL224, KL360, KL379, } \\
\text { KL611, KL519 }\end{array}$ & $\begin{array}{l}\text { sym } 101,41 \\
55,56,57 \\
60,64\end{array}$ & Schauser et al. 1998; Shibata et al.* \\
\hline Sym 8 & Hist-, Ami+ & $\ldots$ & $\ldots$ & $5361-33$ & $\ldots$ & Schauser et al. 1998 \\
\hline Sym10 & Hist-, Ami+ & $\ldots$ & $\ldots$ & $2572-77.1$ & $\ldots$ & Schauser et al. 1998 \\
\hline Albl & Hist-, Ami+ & alb1-1 to -3 & & 16-3F, fix 1, S64 & sym 74 & $\begin{array}{l}\text { Imaizumi-Anraku et al. 1997; } \\
\text { Kawaguchi et al. 2002; Yano, } \\
\text { Kawaguchi, and Hayashi* }\end{array}$ \\
\hline Crinkle & Hist-, Ami+ & crinkle -1 to -3 & LKL515(sym58) & $1-1 \mathrm{H}, \mathrm{S} 66,1-5 \mathrm{~A}$ & sym 79 & $\begin{array}{l}\text { Kawaguchi et al. 2002; Tansengco et al. } \\
\text { 2003; Yano, Kawaguchi, and Hayashi* }\end{array}$ \\
\hline Sym 80 & Hist-, Ami+ & $\ldots$ & $\ldots$ & $\mathrm{N} 2$ & $\ldots$ & Yano, Kawaguchi, and Hayashi* \\
\hline Sen 1 & Fix-, Ami+ & $\begin{array}{l}\text { sym } 11, \text { sym61, } \\
\text { sym75(sen } 1)\end{array}$ & $\ldots$ & $\begin{array}{l}\text { KU3-13, KL1174, fix6, fix9, } \\
\text { s88 }\end{array}$ & $\begin{array}{l}\text { sym } 11, \\
\text { sym61, } \\
\text { sym } 75\end{array}$ & $\begin{array}{l}\text { Schauser et al. 1998; Kawaguchi et al. } \\
\text { 2002; Suganuma et al. } 2003\end{array}$ \\
\hline Sst1 & Fix-, Ami+ & sst $1-1$ to 5 & $\ldots$ & 282-936, fix7, fix 13, s89 & $\begin{array}{l}\text { sym } 13, \\
\text { sym } 81\end{array}$ & $\begin{array}{l}\text { Krusell et al. 2005; Schauser et al. } \\
\text { 1998; Kawaguchi et al. } 2002\end{array}$ \\
\hline Sym43 & Fix-, Ami+ & $\ldots$ & sym103 & cAc17.2.1, G629-21 & & Umehara, Kumagai, and Kouchi* \\
\hline Fen1 & Fix-, Ami+ & $\ldots$ & $\ldots$ & $9-5 B$ & sym 76 & $\begin{array}{l}\text { Imaizumi-Anraku et al. 1997; } \\
\text { Kawaguchi et al. } 2002\end{array}$ \\
\hline Sym104 & Fix-, Ami+ & $\ldots$ & $\ldots$ & M89-21 & $\ldots$ & Hossain, Umehara, and Kouchi* \\
\hline Sym105 & Fix-, Ami+ & $\ldots$ & $\ldots$ & M202-24 & $\ldots$ & Hossain, Umehara, and Kouchi* \\
\hline Ign1 & Fix-, Ami+ & $\ldots$ & $\ldots$ & $56 \mathrm{M}$ & $\ldots$ & Kumagai et al.* \\
\hline Sym 40 & Hist- & sym40and sym 44 & $\ldots$ & cAc38.1, cAc39.1 & $\ldots$ & Yokota, Sandal, and Stougaard* \\
\hline Sym67 & Hist- & $\ldots$ & $\ldots$ & KL770 & $\ldots$ & Yokota, Sandal, and Stougaard* \\
\hline Sym102 & Fix- & $\ldots$ & $\ldots$ & $\ldots$ & $\ldots$ & Umehara and Kouchi* \\
\hline Prh1 & Fix- & $\ldots$ & $\ldots$ & $\ldots$ & $\ldots$ & Karas et al. 2005 \\
\hline
\end{tabular}

${ }^{\text {a }}$ Likely mutant alleles have been found by low-resolution mapping or with very few complementation crosses of mutants with similar phenotypes; $*=$ this publication. 
2). Flanking markers for each locus are indicated (Table 1). This collection of data will provide a framework for the future assignment of new loci and the characterization of alleles of already assigned loci. Altogether, this platform will speed up the early categorization of mutant lines and enable a faster and more efficient characterization of new mutants. In addition, the resource described in this work provides an overview of available alleles (Table 2) and various ongoing activities in different laboratories. The mutant resource described here is comparable to the pea collection (Borisov et al. 2004) and, with the genetic tools available in Lotus spp., it is predicted to have a significant impact throughout the legume family. A high level of synteny between different legumes has already been shown in the Harl region between the genus Lotus and soybean, extending even to Arabidopsis (Krusell et al. 2002; Searle et al. 2003). In the SymRK and Nfr5 regions on chromosome 2, synteny also was found in the genus Lotus and pea (Madsen et al. 2003; Stracke et al. 2003). Furthermore, genome sequencing data and mapping data have been used to make syntenic comparisons among Lotus and Medicago spp. and other legumes (Choi et al. 2004; Udvardi et al. 2005; Young et al. 2005). Therefore, map positions provided here can be expected to predict which Sym genes or loci in Lotus spp., pea, and Medicago spp. are likely to be orthologous. This, in turn, should enable characterization of genes from more recalcitrant legumes, once a gene has been isolated from a model legume, forming a basis for comparative genetics.

New tools for Lotus genetics and molecular characterization of isolated mutants have been developed. We have shown that $83 \%$ of the tested microsatellite markers from the MG-20 $\times$
II

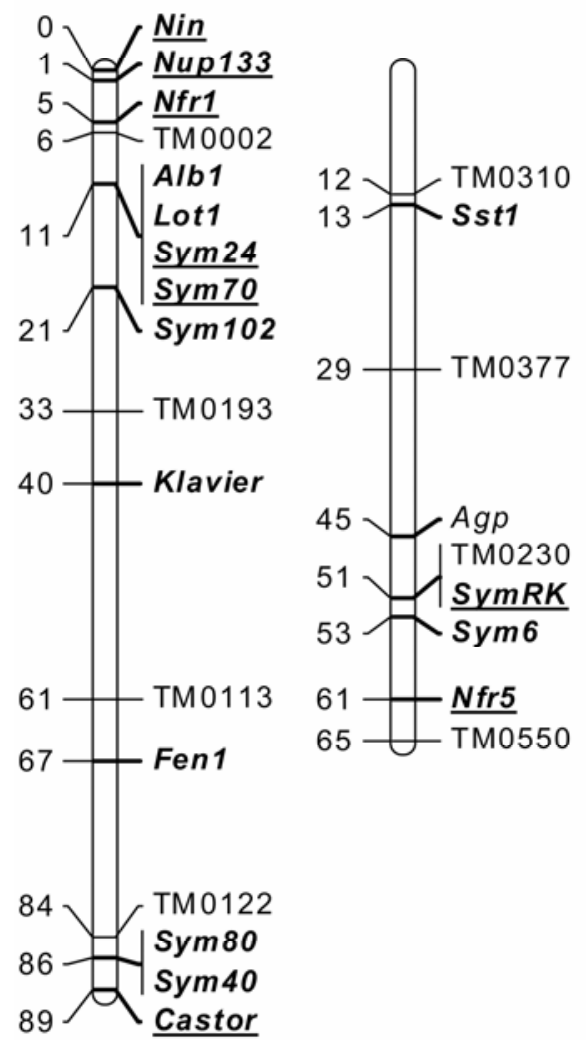

III

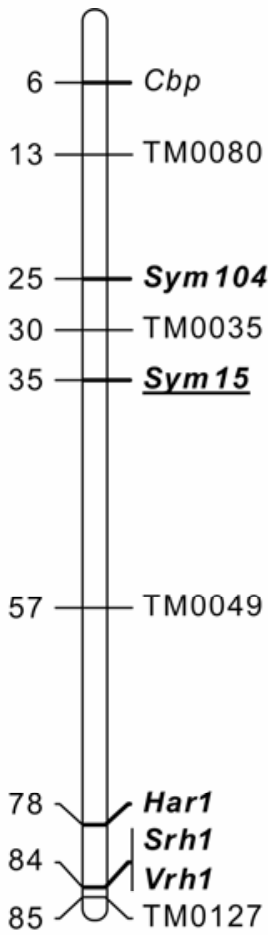

Gifu linkage map were directly transferable to the L. filicaulis $\times$ Gifu map as either dominant or codominant markers. Because microsatellite markers were developed from MG-20 sequence information, it was not surprising that dominant markers, in most cases, detected the Gifu allele. As expected, transfer of markers from an intraspecific map to a more polymorphic interspecific map is relatively easy. Transfer of markers and linkage mapping allowed a direct comparison of the Gifu $\times$ MG-20 and L. filicaulis $\times$ Gifu F2 maps as well as the L. filicaulis $\times$ Gifu RIL map with the Gifu $\times$ MG-20 F2 map. Co-linearity was very pronounced, suggesting, for example, that positional cloning projects can be running in parallel between mapping populations with different parents. This was used in the mapbased cloning of Harl and Nfr5 (Krusell et al. 2002; Madsen et al. 2003). The alignment of F2 and RIL maps also identified regions where genetic resolution is possible or advantageous in only one parental combination. By combining the information from the two mapping populations, it is possible to map and use positional cloning in most of the L. japonicus genome. One region that remains problematic in the $\mathrm{MG}$-20-based maps localizes to the top of MG-20 chromosome 1 , where a large region with suppressed recombination is located. Some "stacked" markers of this region can be ordered in the L. filicaulis-based maps; however, in L. filicaulis $\times$ Gifu crosses, there is significantly distorted segregation on most of linkage group I (chromosome 1), with a preponderance of $L$. filicaulis alleles. Fortunately, L. burttii recently was identified as a third crossing partner (Kawaguchi et al. 2005) and the L. burttii $\times$ Gifu map has only minor suppression of recombination on the top of chromosome 1. L. burttii $\times$ Gifu populations provide the
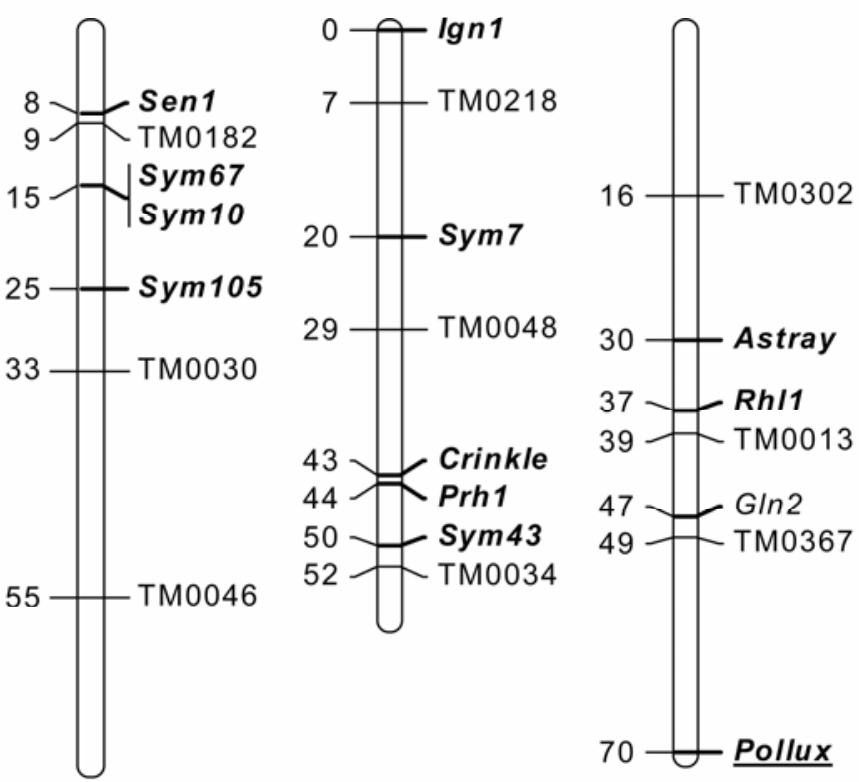

Fig. 3. Position of symbiotic (Sym) genes and selected microsatellite markers on the genetic map of Lotus japonicus Gifu. Loci with a Nod ${ }^{-}$mutant phenotype are underlined. Ljchp and Ljagp were isolated from two promoter-trap lines tagging putative symbiotic genes. Ljgln2 is mutated in a photorespiratory mutant. 
necessary resolution and can be used for map-based cloning of genes in this region. The level of polymorphism between Gifu and $L$. burttii is intermediate between that found in Gifu and $L$. filicaulis and Gifu and MG-20 (Kawaguchi et al. 2005).

In this article, we describe the development of, and mapping with, two RIL collections developed with an ecotype MG-20 and a related diploid Lotus sp. (L. filicaulis). These RILs will be a valuable resource to determine the segregation of various traits, such as disease resistance, symbiotic properties, and many other biological characters, and for subsequent mapping and map-based cloning efforts. For the L. filicaulis-derived RILs, phenotypic differences are expected to be more pronounced than for RILs based on MG-20. L. filicaulis originates from the Mediterranean area (Algeria), which has a very different environment than Japan (where Gifu and MG-20 were collected). Therefore, these parent plants are expected to have adapted to quite different environmental conditions. The variations among RILs might be even bigger than between the parents due to new combinations of alleles. L. burttii was crossed to L. japonicus Gifu and the development of RILs from the F2 population is ongoing. L. burttii was collected in Pakistan and represents another source of genetic and biological variation. Recombinant inbred lines were also developed from a Gifu $\times$ L. japonicus Funakura F2 population. Although Gifu and Funakura are relatively closely related (2 to $3 \%$ polymorphism in amplified fragment

Table 3. Microsatellite markers for low-resolution mapping ${ }^{\mathrm{a}}$

\begin{tabular}{lccc}
\hline Marker & Chr. & Map position & Bottom of chr. \\
\hline TM0002 & 1 & 5.6 & $\ldots$ \\
TM0193 & $\mathbf{1}$ & $\mathbf{3 2 . 5}$ & $\ldots$ \\
TM0113 & $\mathbf{1}$ & $\mathbf{6 0 . 9}$ & $\ldots$ \\
TM0122 & 1 & 83.8 & 89.4 \\
TM0310 & 2 & 12.4 & $\ldots$ \\
TM0377 & $\mathbf{2}$ & $\mathbf{2 9 . 0}$ & $\ldots$ \\
Vic6 & 2 & $29-35$ & $\ldots$ \\
TM0230 & 2 & 51.4 & $\ldots$ \\
TM0550 & 2 & 64.6 & 65.4 \\
TM0080 & 3 & 13.3 & $\ldots$ \\
TM0035 & $\mathbf{3}$ & $\mathbf{3 0 . 0}$ & $\ldots$ \\
TM0049 & $\mathbf{3}$ & $\mathbf{5 6 . 7}$ & $\ldots$ \\
TM0127 & 3 & 84.8 & 86.4 \\
TM0182 & 4 & 8.8 & $\ldots$ \\
TM0030 & $\mathbf{4}$ & $\mathbf{3 3 . 0}$ & $\ldots$ \\
TM0046 & 4 & 55.4 & 70.5 \\
TM0218 & 5 & 7.2 & $\ldots$ \\
TM0048 & $\mathbf{5}$ & $\mathbf{2 9 . 0}$ & $\ldots$ \\
TM0034 & 5 & 51.8 & 56.6 \\
TM0302 & 6 & 16.0 & $\ldots$ \\
TM0013 & $\mathbf{6}$ & $\mathbf{3 8 . 5}$ & $\ldots$ \\
TM0367 & 6 & 48.6 & 70.2 \\
\hline
\end{tabular}

${ }^{a}$ Indicated in bold is a minimal set of primers to cover the six chromosomes (Chr.) of Lotus spp. The map positions shown are for Lotus japonicus Gifu from the cross to MG-20. The red stem or green stem locus Vic6 is a phenotypic marker. length polymorphism), these RILs turned out to be valuable for examining the role of glutamine synthetase in plant biomass accumulation (Harrison et al. 2004; Limami et al. 1999).

With the development of several hundred microsatellite markers corresponding to sequenced TAC clones with approximately 10 genes on each clone, the genetic maps available for the genus Lotus are directly related to the genomic sequence. Combining information from various linkage maps and the genome sequence, map-based cloning in L. japonicus is now quite straightforward. We have shown that a number of important genes for mycorrhizal and rhizobial symbiosis can be isolated using this system. Exploiting biological diversity reflected, for example, in RILs can be used to address other biological questions relevant to both model and crop legumes which should benefit the whole legume community.

\section{MATERIALS AND METHODS}

\section{Plant material.}

The inbred L. japonicus B-129 S9 Gifu germplasm is described by Stougaard and Beuselinck (1996). Ecotype Miyakojima MG-20 is described by Kawaguchi (2000). In the crosses for low-resolution mapping, MG-20 normally is used as the female parent because this gives a higher number of successful crosses. L. filicaulis was obtained from W. F. Grant. The L. filicaulis $\times$ L. japonicus Gifu F2 mapping population was described by Sandal and associates (2002). By selfing of this mapping population until the S8 generation, recombinant inbred lines were obtained. The mutants have been named according to Stougaard and associates (1999). For germination, seeds were treated for 7 min in 95 to $97 \% \mathrm{H}_{2} \mathrm{SO}_{4}$, washed several times in water, sterilized with $0.5 \% \mathrm{NaHOCl}$ for $20 \mathrm{~min}$, and washed as before. Seeds were kept in sterile water overnight before sowing. The screening for symbiotic mutants with a $\mathrm{Nod}^{-}$phenotype (no nodule development) was done after 6 to 7 weeks and, for the Hist $^{-}$(partially developed nodules) and $\mathrm{Fix}^{-}$(nodules that cannot fix nitrogen) mutants, after 4 to 6 weeks. The arbuscular mycorrhizal infection (Ami) phenotype for some of the mutants was determined in previous studies (Kistner et al. 2005; Senoo et al. 2000; Solaiman et al. 2000; Wegel et al. 1998).

\section{DNA preparations.}

DNA from the general F2 and RIL mapping populations was prepared with a modified cetyltrimethylammonium bromide (CTAB) method. Leaf tissue ( $1 \mathrm{~g})$ was crushed in liquid nitrogen with two porcelain beads in a $10-\mathrm{ml}$ plastic centrifuge tube by vortexing. The beads were removed and $5 \mathrm{ml}$ of CTAB buffer (2\% CTAB, $1.4 \mathrm{M} \mathrm{NaCl}, 20 \mathrm{mM}$ EDTA, pH 8.0, and $100 \mathrm{mM}$ Tris- $\mathrm{HCl}, \mathrm{pH} 8.0$ ) preheated to $60^{\circ} \mathrm{C}$ was added. The tubes were incubated at $60^{\circ} \mathrm{C}$ for 30 to $60 \mathrm{~min}$ and mixed a few times during the incubation. Chloroform/isoamylalcohol $(5 \mathrm{ml}$ at 24:1) was added. The tubes were mixed gently and centri-

Table 4. New alleles of previously published sym mutants confirmed by sequencing are listed together with the identified mutation ${ }^{\mathrm{a}}$

\begin{tabular}{lllll}
\hline sym locus & Phenotype & New allele & \multicolumn{1}{c}{ DNA mutation } & Amino acid change \\
\hline nfr1-3 & Nod-, Ami- & N38 & G 1003 to A & G 335 to R \\
nfr1-4 & Nod-, Ami- & G71-23 & G 1145 to A & C 382 to stop \\
nfr5-4 & Nod-, Ami- & S4-1 & G 1415 to A & G 472 to E \\
nfr5-5 & Nod-, Ami- & S58-1 & G 1212 to A & W 404 to stop \\
nfr5-6 & Nod-, Ami- & B31-E & C 237 deleted & Frameshift \\
har1-6 & Nod++ & SL419-4 & T 737 to A $~$ & L 246 to H \\
nup133-4 & Nod-, Ami- & EMS247(sym26) & G 4496 to A, 3' splice site & R993 to V, E994 to stop \\
symRK-12 & Nod-, Ami- & 8-4H & Large insertion at 5' untranslated region & $\ldots$ \\
castor-19 & Nod-, Ami- & G00532-21 & Deleted & $\ldots$ \\
castor-20 & Nod-- & LKL186-4 & C 2234 to G & S745 to stop \\
\hline
\end{tabular}

\footnotetext{
${ }^{\text {a }}$ Position of the mutation is indicated in the coding region (for nup133-4 in the gene); A of the initiator methionine codon is position 1.
} 
fuged at $8,000 \mathrm{rpm}$ for $10 \mathrm{~min}$. The water phase was transferred to a new tube and $5 \mu \mathrm{l}$ of RNAse $(10 \mathrm{mg} / \mathrm{ml}$ of stock) was added and incubated at $37^{\circ} \mathrm{C}$ for $30 \mathrm{~min}$. The tubes were placed on ice for $5 \mathrm{~min}$ and 0.6 volumes of ice-cold isopropanol was added. The tubes were mixed gently by turning, incubated at $-20^{\circ} \mathrm{C}$ overnight, centrifuged for 6 min at $6,000 \mathrm{rpm}$ at $4^{\circ} \mathrm{C}$, washed with $70 \%$ ethanol, and centrifuged again. The ethanol was removed and the pellets were air dried. The DNA was redissolved in 100 to $300 \mu \mathrm{l}$ of $10 \mathrm{mM}$ TrisHCl, pH 8.0.

DNA for mutant populations was prepared by placing a leaflet (or trifoliate for small leaves) in an Eppendorf tube containing $35 \mu \mathrm{l}$ of $0.5 \mathrm{~N} \mathrm{NaOH}$. The tissue was ground using a plastic pistil and a drilling machine until no large tissue parts were present. The tube was centrifuged for $1 \mathrm{~min}$ at 13,000 rpm and 10 to $20 \mu \mathrm{l}$ of the supernatant was transferred to a new Eppendorf tube containing $490 \mu \mathrm{l}$ of $100 \mathrm{mM}$ TrisHCl, pH 8.0. From this DNA preparation, $5 \mu \mathrm{l}$ was used in a standard PCR reaction. This type of preparation works only for small PCR fragments like microsatellite markers.

\section{Markers.}

Microsatellite markers polymorphic between L. japonicus ecotypes Gifu and Miyakojima for each of the sequenced TAC clones were used for mapping (Asamizu et al. 2003; Kaneko et al. 2003; Kato et al. 2003; Nakamura et al. 2002; Sato et al. 2001). In PCR reactions for the populations from L. filicaulis crosses, the annealing temperature was lowered from 55 to $54^{\circ} \mathrm{C}$, the number of cycles was 37 , and the products were separated on 2 or $2.5 \%$ agarose gels. Initially, PCR on DNA from 44 plants was used to determine the linkage group and the approximate map position. For the informative markers, the remaining plants were also tested by PCR.

The plastid glutamine synthetase gene $(G \ln 2)$ (Márquez et al. 2005; Orea et al. 2002) was mapped in the L. filicaulis $\times L$. japonicus Gifu mapping population as a cleaved amplified polymorphic sequence (CAPS) marker amplified with the primers 5'-CCTTCGCCACCAGGACC-3' and 5'-CATCAATGTTT GTCCAGATGC-3' with an annealing temperature of $55^{\circ} \mathrm{C}$ and subsequently digested with $R s a \mathrm{I}$. Mutation of $G \ln 2$ created a photorespiratory mutant (Márquez et al. 2005; Orea et al. 2002).

Ljcbp (Webb et al. 2000) (E. Tuck, unpublished data) and Ljagp (N. Rispail, unpublished data) were isolated from two promoter-trap lines tagging putative symbiotic genes. The $L j c b p$ sequence is present on a contig containing TM0106 and Ljagp was mapped as a CAPS marker (TaqI) in the L. filicaulis $\times L$. japonicus Gifu mapping population with the primer set: 5'CTAGACACACCCAGGCCATAGC-3' and 5'-GTCCAAGAC CACTGTACTTATGCTC-3'.

\section{Map calculation and map drawing.}

The linkage groups have been numbered according to Gifu chromosome size. F. ex. linkage group I corresponds to the largest Gifu chromosome (chromosome 1) (Sandal et al. 2002). MAPMAKER/EXP. version 3.0b (Lander et al. 1987; Lincoln et al. 1992) and Joinmap version 2.0 for Apple computers (Stam and Van Ooijen 1995) were used to calculate the maps. Mapchart 2.1 (Voorrips 2002) was used to draw the map. In the alignment, the L. japonicus Gifu map was used. To test the quality of the data and the mapping, the color mapping procedure was used (Kiss et al. 1998).

\section{ACKNOWLEDGMENTS}

Finn Pedersen is thanked for taking care of the plants. T. Ketelsen is thanked for technical assistance. The Institute of Grassland and Environmental Research is grant-aided by the Biotechnology and Biological Sciences Research Council, N. Rispail was funded by the European Union
(EU) RTN HPRN-CT-2000-00086 Lotus; E. Tuck was funded by a studentship from the University of Wales, Aberystwyth. Research in K. Szczyglowski's laboratory is supported by Agriculture and Agri-Food Canada Crop Genomics Initiative and research grant no. 3277A01 from National Sciences and Engineering Research Council. Research in the laboratories of M. Hayashi, M. Kawaguchi, H. Kouchi, and R. Ohtomo is supported by CREST/JST. Research in A. J. Marquez's laboratory is supported by EU project MRTN-CT-2003-505227 and BFU2005-03120 (Spain). T. G. Radu was supported by the EU training network Integral.

\section{LITERATURE CITED}

Asamizu, E., Kato, T., Sato, S., Nakamura, Y., Kaneko, T., and Tabata, S. 2003. Structural analysis of a Lotus japonicus genome. IV. Sequence features and mapping of seventy-three TAC clones which cover the 7.5 $\mathrm{Mb}$ regions of the genome. DNA Res. 10:115-122.

Borisov, A. Y., Danilova, T. N., Koroleva, T. A., Naumkina, T. S., Pavlova, Z. B., Pinaev, A. G., Shtark, O. Y., Tsyganov, V. E., Voroshilova, V. A., Zhernakov, A. I., Zhukov, V. A., Belimov, A. A., Safronova, V. I., Dietz, K.-J., and Tikhonovich, I. A. 2004. Regulatory genes of pea (Pisum sativum L.) controlling development of its symbiotic systems: Fundamentals and applications. Pages 113-114 in: 5th Eur. Conf. Grain Legumes; 2nd Int. Conf. Legume Genomics Genet., Dijon, France.

Burr, B., and Burr, F. A. 1991. Recombinant inbreds for molecular mapping in maize: Theoretical and practical considerations. Trends Genet. 7:55-60.

Buzas, D. M., Lohar, D., Sato, S., Nakamura, Y., Tabata, S., Vickers, C. E., Stiller, J., and Gresshoff, P. M. 2005. Promoter trapping in Lotus japonicus reveals novel root and nodule GUS expression domains. Plant Cell Physiol. 46:1202-1212.

Choi, H.-K., Mun, J.-H., Kim, D.-J., Zhu, H., Baek, J.-M., Mudge, J., Roe, B., Ellis, N., Doyle, J., Kiss, G. B., Young, N. D., and Cook, D. R. 2004. Estimating genome conservation between crop and model legume species. Proc. Natl. Acad. Sci. U.S.A. 101:15289-15294.

Dobzhansky, T., and Pavlovsky, O. 1958. Interracial hybridization and breakdown of coadapted gene complexes in Drosophila paulistorum and Drosophila willistoni. Proc. Natl. Acad. Sci. U.S.A. 44:622-629.

Handberg, K., and Stougaard, J. 1992. Lotus japonicus, an autogamous, diploid legume species for classical and molecular genetics. Plant J. 2:487-496.

Harrison, J., Hirel, B., and Limami, A. 2004. Variation in nitrate uptake and assimilation between two ecotypes of Lotus japonicus and their recombinant inbred lines. Physiol. Plant. 120:124-131.

Hayashi, M., Miyahara, A., Sato, S., Kato, T., Yoshikawa, M., Taketa, M., Hayashi, M., Pedrosa, A., Onda, R., Imaizumi-Anraku, H., Bachmair, A., Sandal, N., Stougaard, J., Murooka, Y., Tabata, S., Kawasaki, S., Kawaguchi, M., and Harada, K. 2001. Construction of a genetic linkage map of the model legume Lotus japonicus using an intraspecific $\mathrm{F}_{2}$ population. DNA Res. 8:301-310.

Imaizumi-Anraku, H., Kawaguchi, M., Koiwa, H., Akao, S., and Syono, K. 1997. Two ineffective-nodulating mutants of Lotus japonicus-Different phenotypes caused by the blockage of endocytotic bacterial release and nodule maturation. Plant Cell Physiol. 38:871-881.

Imaizumi-Anraku, H., Takeda, N., Charpentier, M., Perry, J., Miwa, H. Umehara, Y., Kouchi, H., Murakami, Y., Mulder, L., Vickers, K., Pike, J., Downie, J. A., Wang, T., Sato, S., Asamizu, E., Tabata, S., Yoshikawa, M., Murooka, Y., Wu, G.-J., Kawaguchi, M., Kawasaki, S., Parniske, M., and Hayashi, M. 2005. Plastid proteins crucial for symbiotic fungal and bacterial entry into plant roots. Nature 433:527-531.

Jiang, Q., and Gresshoff, P. M. 1997. Classical and molecular genetics of the model legume Lotus japonicus. Mol. Plant-Microbe Interact. 10:59-68.

Kaneko, T., Asamizu, E., Kato, T., Sato, S., Nakamura, Y., and Tabata, S. 2003. Structural analysis of a Lotus japonicus genome. III. Sequence features and mapping of sixty-two TAC clones which cover the $6.7 \mathrm{Mb}$ regions of the genome. DNA Res. 10:27-33.

Karas, B., Murray, J., Gorzelak, M., Smith, A., Sato, S., Tabata, S., and Szczyglowski, K. 2005. Invasion of Lotus japonicus root hairless 1 by Mesorhizobium loti involves the nodulation factor-dependent induction of root hairs. Plant Physiol. 137:1331-1344.

Kato, T., Sato, S., Nakamura, Y., Kaneko, T., Asamizu, E., and Tabata, S. 2003. Structural analysis of a Lotus japonicus genome. V. Sequence features and mapping of sixty-four TAC clones which cover the $6.4 \mathrm{Mb}$ Regions of the genome. DNA Res. 10:277-285.

Kawaguchi, M. 2000. Lotus japonicus "Miyakojima" MG-20: An early flowering accession suitable for indoor handling. J. Plant Res. 113:507-509.

Kawaguchi, M., Imaizumi-Anraku, H., Koiwa, H., Niwa, S., Ikuta, A., Syono, K., and Akao, S. 2002. Root, root hair, and symbiotic mutants of the model legume Lotus japonicus. Mol. Plant-Microbe Interact. 15:1726. 
Kawaguchi, M., Pedrosa-Harand, A., Yano, K., Hayashi, M., Murooka, Y., Saito, K., Nagata, T., Namai, K., Nishida, H., Shibata, D., Sato, S., Tabata, S., Hayashi, M., Harada, K., Sandal, N., Stougaard, J., Bachmair, A., and Grant, W. F. 2005. Lotus burttii takes a position of the third corner in the Lotus molecular genetics triangle. DNA Res. 12:69-77.

Kiss, G. B., Kereszt, A., Kiss, P., and Endre, G. 1998. Colormapping: A non-mathematical procedure for genetic mapping. Acta Biol. Hung. 49:125-142.

Kistner, C., Winzer, T., Pitzschke, A., Mulder, L., Sato, S., Kaneko, T., Tabata, S., Sandal, N., Stougaard, J., Webb, K. J., Szczyglowski, K., and Parniske, M. 2005. Seven Lotus japonicus genes required for transcriptional reprogramming of the root during fungal and bacterial symbiosis. Plant Cell 17:2217-2229.

Krusell, L., Madsen, L. H., Genua, A., Szczyglowski, K., Aubert, G., Duc, G., Sato, S., Tabata, S., de Bruijn, F., Pajuelo, E., Sandal, N., and Stougaard, J. 2002. A receptor-like kinase mediates shoot control of root development and nodulation. Nature 420:422-426.

Krusell, L., Krause, K., Ott, T., Desbrosses, G., Kraemer, U., Sato, S., Nakamura, Y., Tabata, S., James, E., Sandal, N., Stougaard, J., Kawaguchi, M., Miyamoto, A., Suganuma, N., and Udvardi, M. 2005. The sulfate transporter SST1 is crucial for symbiotic nitrogen fixation in Lotus japonicus root nodules. Plant Cell 17:1625-1636.

Lander, E. S., Green, P., Abrahamson, J., Barlow, A., Daly, M. J., Lincoln, S. E., and Newburg, L. 1987. MAPMAKER: An interactive computer package for constructing primary genetic linkage maps of experimental and natural populations. Genomics 1:174-181.

Limami, A., Phillipson, B., Ameziane, R., Pernollet, N., Jiang, Q., Roy, R., Deleens, E., Chaumont-Bonnet, M., Gresshoff, P. M., and Hirel, B. 1999. Does root glutamine synthetase control plant biomass production in Lotus japonicus L.? Planta 209:495-502.

Lincoln, E. S., Daly, M. J., and Lander, E. S. 1992. Construction genetic maps with MAPMAKER/EXP 3.0, in: Whitehead Institute Technical Report, 3rd ed. Whitehead Institute, Cambridge, MA, U.S.A.

Madsen, E. B., Madsen, L. H., Radutoiu, S., Olbryt, M., Rakwalska, M., Szczyglowski, K., Sato, S., Kaneko, T., Tabata, S., Sandal, N., and Stougaard, J. 2003. A receptor kinase of the LysM type is involved in legume perception of rhizobial signals. Nature 425:637-640.

Márquez, A. J., Betti, M., Garciá-Calderón, M., Pal'ove-Balang, Diaz, P., and Monza, J. 2005. Nitrate assimilation in Lotus japonicus. J. Exp. Bot. 56:1741-1749.

Mitchell-Olds, T. 1995. Interval mapping of viability loci causing heterosis in Arabidopsis. Genetics 140:1105-1109.

Nakamura, Y., Kaneko, T., Asamizu, E., Kato, T., Sato, S., and Tabata, S 2002. Structural analysis of a Lotus japonicus genome. II. Sequence features and mapping of sixty-five TAC clones which cover the $6.5 \mathrm{Mb}$ regions of the genome. DNA Res. 9:63-70.

Nishimura, R., Hayashi, M., Wu, G. J., Kouchi, H., Imaizumi-Anraku, H., Murakami, Y., Kawasaki, S., Akao, S., Ohmori, M., Nagasawa, M., Harada, K., and Kawaguchi, M. 2002a. HAR1 mediates systemic regulation of symbiotic organ development. Nature 420:426-429.

Nishimura, R., Ohmori, M., Fujita, H., and Kawaguchi, M. 2002b. A Lotus basic leucine zipper protein with a RING-finger motif negatively regulates the developmental program of nodulation. Proc. Natl. Acad. Sci. U.S.A. 99:15206-15210.

Oka-Kira, E., Tateno, K., Miura, K., Haga, T., Hayashi, M., Harada, K., Sato, S., Tabata, S., Shikazono, N., Tanaka, A., Watanabe, Y., Fukuhara, I., Nagata, T. and Kawaguchi, M. klavier (klv), a novel hypernodulation mutant of Lotus japonicus affected in vascular tissue organization and floral induction. Plant J. In press.

Ooki, Y., Banba, M., Yano, K., Maruya, J., Sato, S., Tabata, S., Saeki, K., Hayashi, M., Kawaguchi, M., Izui, K., and Hata, S. 2005. Characterization of the Lotus japonicus symbiotic mutant lot 1 that shows a reduced nodule number and distorted trichomes. Plant Physiol. 137:1261-1271.

Orea, A., Pajuelo, P., Pajuelo, E., Quidiello, C., Romero, J. M., and Márquez, A. J. 2002. Isolation of photorespiratory mutants from Lotus japonicus deficient in glutamine synthetase. Physiol. Plant. 115:352-361.

Pedrosa, A., Sandal, N., Stougaard, J., Schweizer, D., and Bachmair, A 2002. Chromosomal map of the model legume Lotus japonicus. Genetics 161:1661-1672

Perry, J. A., Wang, T. L., Welham, T. J., Gardner, S., Pike, J. M., Yoshida, S., and Parniske, M. 2003. A TILLING reverse genetics tool and a webaccessible collection of mutants of the legume Lotus japonicus. Plant Physiol. 131:866-871

Radutoiu, S., Madsen, L. H., Madsen, E. B., Felle, H. H., Umehara, Y., Grønlund, M., Sato, S., Nakamura, Y., Tabata, S., Sandal, N., and Stougaard, J. 2003. Plant recognition of symbiotic bacteria requires two LysM receptor-like kinases. Nature 425:585-592.

Sandal, N., Krause, K., Frantescu, M., Radutoiu, S., Krusell, L., Madsen, L. H., Kanamori, N., Madsen, E., Tirichine, L., and Stougaard, J. 2005. Mapping and map-based cloning in Lotus japonicus. Pages 217-232 in:
Lotus japonicus Handbook. A. J. Márquez, ed. Springer, Dordrecht, The Netherlands.

Sandal, N., Krusell, L., Radutoiu, S., Olbryt, M., Pedrosa, A., Stracke, S. Sato, S., Kato, T., Tabata, S., Parniske, M., Bachmair, A., Ketelsen, T. and Stougaard, J. 2002. A genetic linkage map of the model legume $\mathrm{Lo}$ tus japonicus and strategies for fast mapping of new loci. Genetics 161:1673-1683

Sato, S., Kaneko, T., and Nakamura, Y. 2001. Structural analysis of a Lotus japonicus genome. I. Sequence features and mapping of fifty-six TAC clones which cover the $5.4 \mathrm{Mbp}$ regions of the genome. DNA Res. 8:311-318.

Schauser, L., Handberg, K., Sandal, N., Stiller, J., Thykjær, T., Pajuelo, E., Nielsen, A., and Stougaard, J. 1998. Symbiotic mutants deficient in nodule establishment identified after T-DNA transformation of Lotus japonicus. Mol. Gen. Genet. 259:414-423.

Schauser, L., Roussis, A., Stiller, J., and Stougaard, J. 1999. A plant regulator controlling development of symbiotic root nodules. Nature 402:191-195.

Searle, I. R., Men, A. E., Laniya, T. S., Buzas, D. M., Iturbe-Ormaetxe, I., Carroll, B. J., and Gresshoff, P. M. 2003. Long-distance signaling in nodulation directed by a CLAVATA1-like receptor kinase. Science 299:109-112

Senoo, K., Solaiman, M. Z., Kawaguchi, M., Imaizumi-Anraku, H., Akao, S., Tanaka, A., and Obata, H. 2000. Isolation of two different phenotypes of mycorrhizal mutants in the model legume plant Lotus japonicus after EMS-treatment. Plant Cell Physiol. 41:726-732.

Solaiman, M. Z., Senoo, K., Kawaguchi, M., Imaizumi-Anraku, H., Akao, S., Tanaka, A., and Obata, H. 2000. Characterization of mycorrhizas formed by Glomus sp. on roots of hypernodulating mutants of Lotus japonicus. J. Plant Res. 113:443-448.

Stam, P., and van Ooijen, J. W. 1995. Joinmap version 2.0: Software for the Calculation of Genetic Linkage Maps. CPRO-DLO, Wageningen, The Netherlands.

Stougaard, J., and Beuselinck, P. R. 1996. Registration of GIFU B-129-S9 Lotus japonicus germplasm. Crop Sci. 36:476.

Stougaard, J., Szczyglowski, K., de Bruijn, F. J., and Parniske, M. 1999. Genetic nomenclature guidelines for the model legume Lotus japonicus. Trends Plant Sci. 4:300-301.

Stracke, S., Kistner, C., Yoshida, S., Mulder, L., Sato, S., Kaneko, T., Tabata, S., Sandal, N., Stougaard, J., Szczyglowski, K., and Parniske, M. 2002. A plant receptor-like kinase required for both bacterial and fungal symbiosis. Nature 417:959-962.

Stracke, S., Sato, S., Sandal, N., Koyama, M. Kaneko, T., Tabata, S., and Parniske, M. 2003. Exploitation of colinear relationships between the genomes of Lotus japonicus, Pisum sativum and Arabidopsis thaliana for positional cloning of a legume symbiosis gene. Theor. Appl. Genet. 108:442-449.

Suganuma, N., Nakamura, Y., Yamamoto, M., Ohta, T., Koiwa, H., Akao, S., and Kawaguchi, M. 2003. The Lotus japonicus Sen1 gene controls rhizobial differentiation into nitrogen-fixing bacteroids in nodules. Mol. Genet. Genomics 269:312-320.

Szczyglowski, K., Shaw, R. S., Wopereis, J., Copeland, S., Hamburger, D. Kasiborski, B., Dazzo, F. B., and de Bruijn, F. J. 1998. Nodule organogenesis and symbiotic mutants of the model legume Lotus japonicus. Mol. Plant-Microbe Interact. 11:684-697.

Tansengco, M. L., Hayashi, M., Kawaguchi, M., Imaizumi-Anraku, H., and Murooka, Y. 2003. Crinkle, a novel symbiotic mutant that affects the infection thread growth and alters the root hair, trichome, and seed development in Lotus japonicus. Plant Physiol. 131:1054-1063.

Tansengco, M. L., Imaizumi-Anraku, H., Yoshikawa, M., Takagi, S. Kawaguchi, M., Hayashi, M., and Murooka, Y. 2004. Pollen development and tube growth are affected in the symbiotic mutant of Lotus japonicus, crinkle. Plant Cell Physiol. 45:511-520.

Thykjær, T., Stiller, J., Handberg, K., Jones, J., and Stougaard, J. 1995. The maize transposable element $A c$ is mobile in the legume Lotus japonicus. Plant Mol. Biol. 27:981-993.

Udvardi, M. K., Tabata, S., Parniske, M., and Stougaard, J. 2005. Lotus japonicus: Legume research in the fast lane. Trends Plant Sci. 10:222-228.

Voorrips, R. E. 2002. MapChart: Software for the graphical presentation of linkage maps and QTLs. J. Hered. 93:77-78.

Webb, K. J., Robbins, M., Wang, T. L., Parniske, M., and Márquez, A. J. 2005. Mutagenesis. Pages 177-186 in: Lotus japonicus Handbook. A. J. Márquez, ed. Springer, Dordrecht, The Netherlands.

Webb, K. J., Skøt, L., Nicholson, M. N., Jørgensen, B., and Mizen, S. 2000. Mesorhizobium loti increases root-specific expression of a calciumbinding protein homologue identified by promoter tagging in Lotus japonicus. Mol. Plant-Microbe Interact. 13:606-616.

Wegel, E., Schauser, L., Sandal, N., Stougaard, J., and Parniske, M. 1998. Mycorrhiza mutants of Lotus japonicus define genetically independent steps during symbiotic infection. Mol. Plant-Microbe Interact. 11:933-936. 
Yoshida, S., and Parniske, M. 2005. Regulation of plant symbiosis receptor kinase through serine and threonine phosphorylation. J. Biol. Chem. 280:9203-9209.

Young, N., Cannon, S., Sato, S., Kim, D., Cook, D., Town, C., Roe, B., and Tabata, S. 2005. Sequencing the gene spaces of Medicago truncatula and Lotus japonicus. Plant Physiol. 137:1174-1181.

Zhang, S., Sandal, N., Polowick, P. L., Stiller, J., Stougaard, J., and Fobert, P. R. 2003. Proliferating floral organs (PFO), a Lotus japonicus gene required for specifying floral meristem determinacy and organ identity, encodes an F-box protein. Plant J. 33:607-619.
AUTHOR-RECOMMENDED INTERNET RESOURCES

Kazusa DNA Research Institute's primary mapping data for L. japonicus Gifu $\times$ L. japonicus MG-20 RILs:

www.kazusa.or.jp/lotus/RIline/RI_map.html

National BioResource Project Legume base Lotus japonicus website: www.shigen.nig.ac.jp/lotusjaponicus/index_e.html

University of Aarhus Bioinformatics Research Center's primary mapping data for L. filicaulis $\times$ L. japonicus Gifu RILs: www.lotusjaponicus.dk 